\title{
Digital technology, human world making and the avoidance of learning
}

\section{Alan Bainbridge}

Canterbury Christ Church University, UK

\author{
Disorder in the house \\ There's a flaw in the system \\ And the fly in the ointment's gonna bring the whole thing down
}

(Calderon and Zevon, 2003)

\section{Abstract}

Despite the widespread application of digital technologies in higher education there is scant evidence to suggest that these have had a significant impact on student learning. A contemporary psychoanalytic model of teaching and learning is offered, which suggests this lack of impact may be the result of an unconscious avoidance with the difficult thinking human learning requires (Kahn and Hasbach, 2012). Anxiety is a component inherent within the process of education, as it continually threatens what is known about the self (Bainbridge and West, 2012). As such, effective human learning requires a 'holding environment', originating in the natural world, where anxieties can be managed (Winnicott, 1964). Paradoxically, digital technologies further separate humans from holding environments and possess an internal logic which leads to an 'untenable violation' (Glendinning, 1995). Consequently, to prevent teachers and learners being overwhelmed by anxiety, unconscious defences are mobilised to avoid difficult thinking. This results in the seductive influence for simplistic solutions to complex problems. Digital technologies therefore become fetishes as they assume power and value beyond their objective state (Berger, 1967; Marx, 1867). The power of the fetish is to confuse and deceive, and in the context of learning, digital technologies continue to enforce the separation of teachers and learners from relational holding environments. The role of the learning developer is to acknowledge the complex nature and difficult nature of education and to not remove the anxiety this creates. 
Keywords: anxiety; unconscious avoidance; fetish; holding environment.

\section{Introduction: disorder in the house}

It seems entirely appropriate to remove the 'fourth wall' (Krasner, 2012) of academic convention and allow the reader a brief insight into how this paper has evolved. I do this as the forthcoming argument may, at times, be rather complex and possibly a little obtuse. Also, as Warren Zevon warns us, it will indicate that there is disorder in the 'house' which may have unforeseen outcomes unless it is addressed. My aim is to highlight the premise that learning is a multi-faceted and messy process. Then, within a novel contemporary psychoanalytic discourse, emphasise the impact of an unconscious anxiety on teaching and learning.

After twenty years of secondary school teaching I took up a post in higher education (HE). During this time I had attempted to find the 'silver bullet' that would provide me with an 'excellent' Ofsted rating, create model pupils and more recently answer the question 'why do the adults I teach still behave in a similar manner to children?'. Alongside these commendable strivings, I was becoming increasingly frustrated as to why the learning and teaching committees I attended so regularly avoided discussing learning and teaching. Instead these were arenas for planning the implementation of virtual learning environments, e-submission and assessment of academic work, preventing plagiarism, monitoring attendance, creating e-portfolios and avatar life forms. Such devices it was argued would bring the student experience (note: experience and not learning) into the $21^{\text {st }}$ Century. It became increasingly apparent that the essentially human activity of teaching and learning was at risk of morphing into a pedagogically perverse application of digital commodities.

I make the case that digital technologies are being imposed upon formal learning environments, particularly focused within $\mathrm{HE}$ and often associated with the 'student experience' agenda (DfES, 2005; HEFCE, 2009). This imposition often reflects what amounts to a thoughtless approach to teaching and learning, in which pedagogy is sidelined by neo-liberal practices of efficiency and surveillance (Hannon and Bretag, 2010; Holley et al., 2011). It will also be noted that as humans construct their physical and psychological world, they increase their separation with the 'original' site for learning; the 
natural world. Importantly, these products of human world-making may develop their own logic, which can confront human flourishing. I argue that formal education is effectively increasing the separation between the human and non-human world and that the unconscious anxiety related to learning represents this dilemma. It will be recommended that the rich complexity and anxiety inherent in teaching and learning is not removed but acknowledged. It is therefore incumbent on those who have a responsibility developing learning to engage with the difficulty of learning and not to be seduced away from difficult thinking by 'digital fetishes'.

\section{Applying the ointment: the imposition of digital technology in higher education}

Digital technologies define the modern world and yet despite their ubiquity, the United Kingdom government judge it necessary to provide policy and strategy documents to encourage their uptake in HE (DfES, 2005; HEFCE, 2009). Kirkwood and Price (2014), in their review of technology-enhanced learning (TEL), note that the $£ 12$ million government allocation represents a significant investment in schools and universities. It is surprising that in a profession that can often be heard bemoaning the lack of fiscal support, that the $£ 12$ million has not had the impact it was expected. This raises questions about the fundamental relationship between TEL and the lived experience of teaching and learning in HE. Holley et al. (2011) make the case that the demands of government policy and strategy are in conflict with HE staff and students, to such an extent, that teachers and learners have become silent voices within the dominant hegemony of neo-liberal managerialism. Hannon and Bretag (2010), from an Australian perspective, also make the case that TEL is a site of contested discourses with very little consensus as to the appropriate pedagogical application of TEL. The silent voices lost within the confusion indicate discomfort, rather than clarity of purpose, which the TEL agenda has unleashed. There is a 'disorder in the house' but what policy makers had hoped would be the ointment (namely TEL), may now have become one of the 'flies' which metaphorically contaminate it.

The imposition of the TEL/e-learning agenda has its foundations neither in the principles nor the practices of pedagogy. Kirkwood and Price (2014) highlight the assumption that TEL will 'just happen' and uncover how confusion over the term 'enhanced' leads to the 
process of learning becoming marginalised. Significant voices in the world of TEL agree; Baume (2013), Beetham (2012), Hannon and Bretag (2010), and Holley et al. (2011) all raise concerns that the technology is taking over from pedagogy and crucially the practices of efficiency, surveillance and an apparent 'opening up' of HE, all detract from thinking about learning. It is telling that Kirkwood and Price (2014) conclude that the drive towards TEL has brought little change in the practice of teaching and learning in HE. I find this research, paradoxically, both comforting and uncomfortable. I am comforted that my subjective experience outlined above is mirrored elsewhere and not a feature of becoming 'out of touch'; yet deeply saddened that education, in its widest sense, is albeit, unconsciously becoming side-lined. Despite this potentially disturbing analysis it is wise to heed Beetham and Sharpe's (2007) advice and to use the rise of TEL to raise questions about pedagogical assumptions.

\section{Considering the disorder: meaning making, human learning and seduction}

If there is 'disorder in the house' this is as it should be, for central to the following debate is the psychoanalytic understanding that human learning is complex, often illogical, and the site of anxiety. Human learning can be distinguished from that of other animals as there is a curiosity and desire to know about the world driven by an 'epistemophilic instinct' (Klein, 1931/1985), alongside the tension that exists between current and new knowledge. The understanding of learning offered here draws upon sociology, ecology and psychoanalysis. The model of human learning that will emerge is one that positions learning at the heart of being human and the concomitant struggle to make meaning in a world that is continually being (re)constructed by human activity. To continue with the metaphor of 'the flies in the ointment' there are a number of elements which need to be considered.

\section{Fly no.1: the social construction of reality}

Berger and Luckmann (1966) posit that human societies are engaged in a process of 'world building'. They argue that the human condition is biologically and anthropologically predicated on the need to build societies where interdependence on each other is fundamental. In doing so, a perceptive, although contentious, distinction between humans and other animals is proposed; they argue that unlike other animals, humans have no 
species-specific environment 'ready' for them. For example, dogs and horses are biologically predisposed to inhabit, what Berger and Luckmann term the 'closed-worlds', of a dog-world or horse-world. The corollary for humans is an 'open-world' that reflects the anthropological incompleteness of early life. Consequently, humans lack strong instincts and compared to other animals spend a disproportionate period of their early life being cared for by others. Thus, the world they are destined to inhabit is not immediately ready and available. Instead, this external world is 'open' to the possibility of being changed as a result of the dialectical interaction between humans and the features of human society, cultural activity and the non-human natural world. In this way, human activity constructs the external (and internal) world. Importantly these products of human agency now become part of the experienced world and consequently, will in turn, influence how human life is experienced and constructed.

The dialectical relationship between humans constructing their world and, in turn, this world having a direct influence on human subjectivity is not without problems. Berger (1967) discusses how the human made world may put a fly in the ointment. In the context of this paper, Berger's ideas allow the role of a product, such as digital technology, to be thought about within the dialogical process of human world making. He argues that once constructed, material and non-material products develop their own logic. Marx (1867) refers to this as commodities having their own 'brain'. The example provided concerns the development of the plough (plow) and, although acknowledging that this does make agriculture easier, it also enforces its own being and logic on others. Hence, the human made product of the plough has an impact on how tilling the soil takes place and wider agricultural activity necessarily develops around it. The warning Berger provides is that the human products resulting from a dialogical relationship with external world(s) have a consequence and logic that was previously unforeseen, and this will often confront and powerfully control the human condition. There are resonances here with Engeström's (2000) Activity Theory and the social construction of knowledge where he draws attention to the role of objects creating contradictions as the site of learning. The argument to be developed here is that digital learning technologies can be viewed through the same lens as the plough. Although the product of human learning, they may now, paradoxically, play a role in contradicting and confronting the process of learning they were designed to support. 


\section{Fly no. 2: separation from the non-human world}

Recent years have seen a considerable increase in what has now been termed ecopsychological or ecopsychoanalytic thinking (Roszak et al., 1995; Dodds, 2011; Kahn and Hasbach, 2012). The significance of combining ecological and psycho-logical/analytic thinking is that this potentially exposes the ontology of Berger and Luckmann's (1966) dialogical human/non-human interactions. From an ecopsychological perspective the development of human thought processes need to be placed in geological time frames. The time spent on the planet by the 'modern human' represents only about $0.003 \%$ of its evolutionary lifespan. Only five or six generations have passed since the Industrial Revolution. What is significant about these comparatively short time periods is that they indicate an imperceptibly small period of time that humans have been living a life that, to an increasingly greater extent, is separated from the non-human, natural world.

Ecopsycholoanalysts consider the recent separation of people from nature as the cause of many of the more negative aspects of modern human behaviour, such as childhood unhappiness (Layard and Dunn, 2009), the increase in mental health issues (Searles, 1960; 1972), addictive behaviours (Glendinning, 1995), detrimental consumerist behaviours (Weintrobe, 2013) and behaviours that damage the ecosystem (Roszak et al., 1995; Dodds, 2011). For most of the evolutionary history, humans were born, in the language of Berger and Luckmann, into a 'closed' human world - one that the process of evolution had designed them to fit. But for whatever reasons, which are not part of this paper, the development of the 'modern' human no longer takes place in nature. Instead there is a disconnect and the social and cultural world must be constructed from the products of human agency.

Within this context, a terrible paradox exists, as to a large extent the products of human activity, those created by the human interaction with the external world, do not make a world that is easier to fit into. Rather, according to Berger (1967), these products impose their own logic that ultimately confronts the status quo, thus creating the situation where humans must continually construct and re-construct their world. It is within this never ending dialogical cycle that the human psyche struggles to survive, since, due to the internal logic of constructed products confronting human actions, the external non-human world can never be constructed to suit the human world. For example, a dog, badger and hedgehog are born fitting into a world that exists relatively unchanged. Not so the lot of humans. How humans deal with not fitting the world they are born into provides an 
opportunity to consider more individually nuanced psychoanalytic perspectives and how learning and technology can become implicated in human meaning making and the motivation to learn. My contention is that the nature of learning may be the flaw in the system that is creating disorder.

\section{The flaw in the system: learning evokes anxiety}

Two 'flies in the ointment' have been identified. The first exposes how the products of human world-making develop their own logic that may confront human flourishing, thus creating anxiety. The second, from an ecopsychological and ecopsychoanalytic perspective, suggests that negative aspects of human behaviour are the result of a continued separation from the non-human world, thus leading to dis/unease. The 'flaw in the system' that is alluded to here is the psychoanalytic principle that, despite an attempt to monitor and control, human learning is both complex and beset with anxiety. A psychoanalytic understanding of human learning is one that, although influenced by very early experiences, is life-long and life-wide. Significantly, learning can be regarded as being situated within 'holding environments' and as the site of identity formation, where the role of a dynamic unconscious is implicated in alleviating anxiety. Hence, to provide insight into the proliferation of digital technologies, a deeper exploration of why human learning can be linked to 'holding environments', and also instigate existential questioning, becomes essential.

\section{Holding environments}

It is a fundamental omission of policy makers, learning developers, and indeed all those involved in teaching/learning relationships, to avoid thinking about where the site of learning may be. Donald Winnicott's (1964/1991) psychoanalytic concept of a 'holding environment' is worth considering within this context, as Winnicott acknowledges that early (and subsequent) learning is not easy, that it creates anxiety which has the potential to prevent subsequent learning from taking place. Winnicott's ideas represent an early form of ecopsychoanalytic thought (Dodds, 2011) as he acknowledged, unlike his psychoanalytic contemporaries, that unconscious processes may have their origins in how an individual interacts with their external environment. The phrase 'holding environment' is used due to Winnicott's appreciation of the role of the external world to support an infant 
who, although not fully cognizant of their world, is acutely aware of the sense of loss experienced when not being cared for. It is the role of the $(\mathrm{m})$ other to physically and psychologically hold and contain the anxieties of the infant and to encourage exploration. Winnicott's ideas can be extended to HE as his interest was in the process of learning about the world; infants and $(\mathrm{m})$ others now become students and teachers, while the holding environment represents the places and spaces where learning is situated.

\section{Anxiety}

Britzman (2003) acknowledges the Freudian assumption that learning inaugurates a crisis, as new knowledge threatens the comforting reality of existing knowledge and therefore what is known about the self. Consequently during learning, the ego, whose role is to regulate adaptation to the external world, is placed under unreasonable pressure to deal with contrasting internal and external demands. This heightened level of anxiety increases the potential for the dynamic unconscious to mobilise its defences. Schleifer (1987) sees this, in the context of Lacan's 'passion for ignorance' not as a passive 'not knowing' but the result of an active dynamic unconscious that seeks to defend against new knowledge. This passion for ignorance, or a desire to hold on to what is known, becomes a barrier to learning; the assimilation of new knowledge can only occur when psychic defences are sufficient to support the potential threat that this may represent.

Learning is therefore not a matter of simple adaptation as in the animal kingdom but involves intimate relationships with significant others who guide, over many years, the 'new person' towards the required social and cultural nuances. It is a process that takes place in 'holding environments' where, through the care of others, an individual can find personal meaning. The need for modern humans to continually engage in social and cultural world construction has resulted in their separation from the natural world and the relationships essential to a supportive holding environment. When the process of world construction is considered within a psychoanalytic pedagogical discourse, it can be seen that learning is a site of considerable anxiety, with the unconscious threat now centred on the process of self-construction (Hinshelwood, 2009). Therefore, the flaw in the system is to not pay sufficient attention to providing learning environments that can encourage caring relationships, which are capable of holding and containing the anxiety that is at the heart of teaching and learning. 


\section{Discussion}

\section{Putting the house in order: why digital technologies detract from learning}

\section{The seduction of digital technology as a fetish}

The increasingly widespread use of digital technologies within HE learning environments represents a response to the anxiety associated with learning. It is not unreasonable to consider learning, particularly early on in the evolution of modern humans, as the development of thought processes and activities that enabled the immediate environment to be manipulated and managed. Such practices involved simple technologies.

Subsequently, from this starting point, it is possible to contend that digital technology is an example of the current peak of human endeavour to construct a world fit for humans. Paradoxically, it has been shown that the culmination of human world and meaning making further separates the human condition from the natural world. In the context of learning, this takes them further away from the caring relationships situated in holding environments where anxiety can be contained. Glendinning (1995) refers to this as an 'untenable violation' which results in an increasing fragmentation of human functioning and disconnect from the natural world. She claims that since the natural world, the primary source of human well-being has become ever more distant and unavailable, so humans have increasingly turned to secondary sources as a site of satisfaction and comfort, including over reliant, fetish-like addictive behaviours related to alcohol, drugs, sex and technology. This gives rise to unconscious reactions which, within the context of HE learning environments, may in turn inhibit suitable responses to teaching and learning situations. Such responses could include behaviours where objects are attributed power and value beyond their immediate objective state, and can therefore become potential objects of fetishism (Freud, 1927; Marx, 1867).

There is here, a terrible paradox. Despite the history of human endeavour to make a world that satisfies deeply held unconscious desires, such efforts only cause the gap between the human and non-human world to become ever more distant. It is therefore possible to envisage, from within a discourse of desire and deeply held feelings of being left unfulfilled, that the reliance of humans on technology in learning environments can be considered a fetish. Peter Berger (1967) predicted such a situation, although not using quite the same psychological language. He recognised how products of human endeavour develop their own logic, incongruent of the human condition, which has the potential to confront human functioning. A positive feedback loop has been established whereby 
human constructed objects now determine the physical and psychological activities of humans and the psyche. This leaves the psyche, that seeks communion with others and nature, left struggling to survive. Hence, the case for what I now argue is an over-reliant, fetish-like, dependency on digital technologies, where the object has attained a value that no longer reflects the original purpose, namely to enhance teaching and learning. From a psychoanalytic perspective this situation does not mean that the world is now inhabited with endless millions of individuals paralysed by feelings of inadequacy, loneliness and a deep-seated fear of annihilation and unable to learn. What psychoanalysis does tell us is that the vast majority of people will be functioning perfectly adequately, and that an array of unconscious defences will be available to protect individuals from being overwhelmed by the potential realisation of this 'untenable violation'. One such defence is of course to avoid the anxieties associated with learning, and to be seduced (unconsciously) by the assumption that a human-made digital device will salve the difficult problem of human learning.

\section{Avoiding difficult knowledge: omnipotent delusions}

Winnicott's (1960/2007) notion of holding environments, and the role of caring relationships to manage difficult knowledge, involves the defence of omnipotent delusion. In this case the infant is protected from a full awareness of their own inadequacies and subsequent total reliance on the $(m)$ other by the delusion that they are in control and that it is their omnipotent wishes that 'magic-up' the breast, a cuddle or soothing words. So, it is also, for digital technologies in the anxiety-ridden environment of lifelong learning. The reliance on and call for increased use of digital technologies defends against the realisation that learning is complex, deeply troubling and is potentially costly, as it involves developing relationships between lecturers and students. The delusion created is that learning can be controlled, indeed, that learning is logical and linear. From the perspective of psychoanalysis, informed by the principles of social constructionism and ecology, nothing could be further from the truth. The omnipotent delusion, represented by an increasing reliance on digital technologies, is a social defence that deceives by averting the gaze from what learning within caring relationships might actually involve. 


\section{Avoiding difficult knowledge: splitting}

Melanie Klein was a colleague of Winnicott who proposed that, throughout the lifespan, anxiety causes individuals to revert to paranoid-schizoid thinking which defends the self by the dichotomous splitting of ideas into good and bad, thereby holding onto good thoughts and feelings and projecting out the bad (Klein, 1931/1985). The continual proliferation of learning technologies may be the result of such a split, where due to the seduction of technology, it unconsciously becomes 'good' and other forms of pedagogy are labelled as 'bad'. The suggestion is that unconscious defences avoid the troubling nature of what learning may actually involve, and the simplistic digital technology response is readily accepted and complex pedagogy is rejected.

Klein also argued that as the infant develops they begin to realise the world is not as black and white as they first supposed and that others beside them have their own needs and wants. The change results in feelings of guilt towards the caregiver and the desire to repair any damage their behaviour may have inflicted. She also identified a more dysfunctional desire to repair known as a manic reparation. This defence protects the individual from guilt by belittling the situation and even carrying out behaviours that make matters worse. Consequently, digital technologies can be considered as manic reparations, as the ability to think about learning and the anxiety it creates becomes subsumed by the pivotal and powerful discourse of strategy and functionality instead of pedagogy. For example, Hannon and Bretag (2013) identified contested discourses represented by three distinct repertoires. The first two are found within policy statements that present digital technologies as (un-problematically) providing cost-effective access to a global market. The third discourse, revealed from the language of learning developers and teachers, considers the role of digital technology as foregrounding a relational approach to pedagogy. What emerges are policy makers, and potentially learning developers, who seduced by the fetish of technology, sincerely believe that digital products are the solution to complex human learning. But it is a cruel seduction and, like all fetish behaviours, it detracts from the real work involved in human learning. This, of course, is too difficult and troubling even to be thought about (Schleifer, 1987; Britzman, 2003). 


\section{Conclusion}

Psychoanalysis teaches us that learning is a complex and difficult process, influenced by defence mechanisms that protect the individual from the anxiety inherent in confronting new knowledge. The use of technology in $\mathrm{HE}$ can therefore be located within a discourse of psychological defences, where the teacher and learner, influenced by an unconscious 'passion for ignorance' and simplistic split thinking, are seduced to avoid engaging with the difficulties and anxieties associated with learning. Instead, the seduction leads to fetish-like confused attempts to find satisfaction in learning mediated by digital technologies. Unfortunately, this technological product of human world making, with its own logic, ultimately confronts and maintains the damaging disruption of the dialogical holding environment relationship.

The responsible moral and pedagogical stance to take is to not simply accept that digital technologies are human products that have the potential to enhance learning. Instead, those in $\mathrm{HE}$ who have a role in thinking about and designing learning situations should be mindful of the seductive power and 'fetish-like' response to technology (Kahn and Hasbach, 2012). Considerable research (Holley et al., 2011; Hannon and Bretag, 2013; Kirkwood and Price, 2014) highlights the disjuncture between the discourse of teachers/lecturers from that provided in teaching and learning policy documents. The former espouse relationships and 'deep learning', while the latter are focused on managerial issues of strategy and function, where the language of efficiency, either glosses over or occludes, pedagogical thinking. The suggestion is not to avoid digital technology but to think care-fully about the role it may have in HE teaching and learning programmes.

Finally, the fourth-wall must be pushed aside again. I was re-writing this paper at the same time as running tutorials for Year Three dissertations and a student came in all flustered, there may have been tears, but if so they were wiped away for me. The student sat with photocopied articles spilling from their knees to the floor, while desperately trying to find 'the form you asked for - it's got my ideas on'. I waited and said nothing giving them time to settle. Sensing the chaos I asked the student to 'just tell me what the idea was'. She looked anxious, continued to hunt for the elusive form and then sighed before spurting out enough information for a PhD. I laughed and told them they had a life times' work already. 
We spent some time trying to identify what the research could be but I was continually pushed to suggest 'how many articles should I read, what about books, do they all have to be in the 2000s?'. I decided to show them this paper and how I work. How my many notes were covered in scribbles and corrections and there were piles of articles and books on the floor. I mentioned how long this piece of writing had taken me. The student seemed astonished and I began to talk about how difficult reading and writing really is. She relaxed (a bit!) and then it became possible to think about the study and not the chaos of notes and articles. The search for the form was possibly a search for security, or a distraction to actually have to think about the chaos, and it seemed my job was to provide the answer. I imagined myself saying, 'You are researching the impact that e-portfolios have on retention of first generation working-class female students in Year One at a Russell Group university. I would expect three book chapters, ten journal articles...' but this would not encourage learning. I also tried to re-imagine the scenario but carried out by e-mail or Skype, and question whether the wiped away tears, chaos of notes, or my own story could have entered these spaces.

There is a moral here and my recommendation is to approach teaching and learning honestly, respectfully and with humanity. We should acknowledge that learning, by definition, catches us off guard and makes us feel uneasy and that learning, or teaching, is complex. Digital technologies are fine and wonderful things and do have a role. They offer, albeit anxiously, a richness of connectivity between the learner and a vast array of difficult knowledge; the potential of MOOCs to disrupt existing knowledge-based power structures; and hard to avoid access to the wonder of comet landings, while at the same time fraud in sport and the horror of man-eating tigers (BBC, 2014). Decisions about the application of digital technologies in HE must be informed by a critical understanding of pedagogy, and this is one that reflects the relational nature of how humans learn best and not by a discourse of managerialism and surveillance.

\section{Acknowledgements}

I am much indebted to Dr Stephen Scoffham and the reviewing editors for taking the time to follow the ideas in this paper and to offer much appreciated support and advice. 


\section{References}

Bainbridge, A. and West, L. (2012) 'Introduction: minding the gap', in Bainbridge, A. and West, L. (eds.) Psychoanalysis and education: minding a gap. London: Karnac, pp. 11-38.

Baume, D. (2013) 'Technology in its Place', Educational Developments, 14(2), pp. 22-23.

BBC (2014) BBC news homepage. Available at: http://www.bbc.co.uk/news/ (Accessed: 13 October 2014).

Beetham, H. (2012) 'Ten years of technology education: what have we really learned?', Educational Developments, 13(2), pp. 1-5.

Beetham, H. and Sharpe, R. (2007) Rethinking pedagogy for a digital age: designing and delivering e-learning. Oxford: Routledge.

Berger, P.L. (1967) The sacred canopy: elements of a sociological theory of religion. New York: Anchor Books.

Berger, P.L. and Luckmann, T. (1966) The social construction of reality: a treatise in the sociology of knowledge. London: Penguin.

Britzman, D.P. (2003) After-education: Anna Freud, Melanie Klein and Psychoanalytic histories of learning. Albany: State University of New York Press.

Calderon, J. and Zevon, W. (2003) Disorder in the house. London: Universal Music Publishing Group.

Department for Education and Skills (2005) Harnessing technology: transforming learning and children's services. Nottingham: DfeS Publications -1296-2005.

Dodds, J. (2011) Psychoanalysis and ecology at the edge of chaos: complexity theory, Deleuze and psychoanalysis for a climate in crisis. East Sussex: Routledge. 
Engeström, Y. (2000) 'Comment on Blackler et al. Activity theory and the social construction of knowledge: a story of four umpires', Organization, 7(2), pp. 301-310.

Freud, S. (1927) 'Fetishism' in The Complete Works of Sigmund Freud (Vol. XXI), (J. Strachey, Trans). London: Hogarth and the Institute of Psycho-analysis, pp. 147157.

Glendinning, C. (1995) 'Technology, trauma and the wild', in Roszak, T., Gomes, M.E. and Kanner, A.D. (eds.) Ecopsychology: restoring the earth, healing the mind. San Francisco: Sierra Club Books, pp. 41-54.

Hannon, J. and Bretag, T. (2010) 'Negotiating contested discourses of learning technologies in higher education', Educational Technology and Society, 13(1), pp. 106-120.

HEFCE with JISC and the Higher Education Academy (2009) Enhancing learning and teaching through technology. Available at: www.hefce.ac.uk/pubs/hefce/2009/09 12/ (Accessed: 28 October 2014)

Hinshelwood, R.D. (2009) 'Do unconscious processes affect educational institutions?', Journal of Clinical Child Psychology and Psychiatry, 14(4), pp. 509-522.

Holley, D., Burns, T., Sinfield, S. and Glass, B. (2011) When worlds collide: the paradox of learning development, e-learning and the $21^{\text {st }}$ Century university', in Hartley, P., Hilsdon, J., Keenan, C., Sinfield, S. and Verity, M. (eds.) Learning development in higher education. Basingstoke: Palgrave Macmillan, pp. 199-211.

Kahn, P.H. Jr. and Hasbach, P.H. (2012) 'Introduction to ecopsychology: science, totems, and the technological species', in Kahn, P.H. Jr., and Hasbach, P.H. (eds.) Introduction to ecopsychology: science, totems, and the technological species. London: The MIT Press, pp. 1-21.

Kirkwood, A. and Price, L. (2014) 'Technology-enhanced learning and teaching in higher education: what is 'enhanced' and how do we know? A critical literature review', Learning, Media and Technology, 39(1), pp. 6-36. 
Klein, M. (1931/1985) Love, guilt and reparation and other works, 1921-1945 (1985 edn). New York: The Free Press.

Krasner, D. (2012) A history of modern drama. London: Wiley.

Layard, R. and Dunn, J. (2009) A good childhood. London: Penguin.

Marx, K. (1867) 'The fetishism of commodities and the secret thereof', in Marx, K. Capital, volume one, commodities and money. Available at: http://web.stanford.edu/ davies/Symbsys100-Spring0708/Marx-CommodityFetishism.pdf (Accessed: 28 October 2014).

Roszak, T., Gomes, M.E. and Kanner, A.D. (eds.) (1995) Ecopsychology: restoring the earth, healing the mind. San Francisco: Sierra Club Books.

Schleifer, R. (1987) 'Lacan's enunciation of the cure of mortality: teaching, transference and desire', College English, 49(7), pp. 801-815.

Searles, H. (1960) The nonhuman environment in normal development and in schizophrenia. New York: International University Press.

Searles, H. (1972) 'Unconscious process in relation to the environmental crisis', Psychoanalytic Review, 59(3), pp. 361-374.

Weintrobe, S. (2013) 'On the love of nature and on human nature: restoring split internal landscapes', in Weintrobe, S. (ed.) Engaging with climate change. East Sussex: Routledge, pp. 199-213.

Winnicott, D.W. (1960/2007) 'The theory of the parent-infant relationship', in Winnicott, D.W. The maturational processes and the facilitating environment. (2007 edn) London: Karnac.

Winnicott, D.W. (1964/1991) The child the family and the outside world. (1991 edn) London: Penguin. 


\section{Author details}

Alan Bainbridge is a Chartered Psychologist, Doctor of Clinical Science and is interested in the contested space between psychoanalytic thought and the processes of education in its widest sense. He has written on how educational professionals develop their professional practice and also, the nature of academic understanding. Together with Linden West, Alan has edited Psychoanalysis and Education: minding a gap (Karnac). 